\title{
GESTÃO DOS MICROSSISTEMAS NO AMBIENTE SÓCIO ESCOLAR: PERCEPÇÃO DE ALUNOS E ALUNAS DO ENSINO TÉCNICO DA REDE PÚBLICA FEDERAL DE PALMAS-TO'
}

http://dx.doi.org/10.5902/2176217110392

\author{
Vonínio Brito de Castro \\ Instituto Federal de Educação, Ciência e Tecnologia \\ do Tocantins, Brasil. \\ Marta Roseli de Azeredo Barichello \\ Universidade Federal de Santa Maria, Brasil.
}

\section{Resumo}

O estudo analisou as percepções de estudantes do ensino técnico subsequente a cerca dos microssistemas no ambiente sócio escolar. Pontuou o desenvolvimento humano a partir das atividades realizadas; descreveu o ambiente sócio escolar conforme a percepção dos alunos; comparou as diferenças e semelhanças de percepções entre gêneros. Os resultados mostram que os institutos federais oferecem cursos extracurriculares à comunidade interna e externa, como determinado na LDB, porém, não atende a demanda; há insatisfação entre os alunos quanto às atividades extracurriculares; as atrações esportivas e atividades de lazer são proporcionais; apesar dos pontos negativos, os estudantes percebem o desempenho positivo dos mesmos em função dos microssistemas.

Palavras-chave: microssistemas, gestão, ambiente escolar.

\section{MANAGEMENT OF THE MICROSSYSTEM IN THE SOCIAL SCHOOL ENVIRONMENT: MALE AND FEMALE STUDENTS' PERCEPTION OF THE TECHINICAL EDUCATION AT A FEDERAL INSTITUTION IN PALMAS}

\begin{abstract}
In this study, the author analized in a technical school, the students' perceptions on the management of microsystems. It has pointed the human development from activities taken in the school environment; it has described the social school environment from those students' perception; it has compared their perceptions differences and similarities. The results show that: the federal institutes offers extracurricular courses to internal and external communities, as established in the LDB, however, they are not sufficient. There is dissatisfaction among students related to extracurricular activities; there is a proportional distribution of sporting and leisure attractions; dispite the negative points, students confessed their positive development due to the microsystems.

Key-words: microsystems, management, school environment.

\footnotetext{
${ }^{1}$ Monografia apresentada ao Curso de Especialização em Gestão Educacional, da Universidade Federal de Santa Maria, como requisito parcial para obtenção do título de especialista em Gestão Educacional.
} 


\section{Introdução}

A escola o aluno se depara com ambientes de características social e ecologicamente diversificadas. O desenvolvimento do aluno é influenciado pela intensidade do seu envolvimento no ambiente, mediado pelos microssistemas, ou seja, por todas as atividades, incluindo os projetos desenvolvidos no cotidiano da escola. Ao mesmo tempo em que a escola é um microssistema no contexto da gestão educacional, é também um macrossistema ao constituir-se de diversas partes menores - auditórios, salas, direção, laboratórios, pátio, cantina - sendo que cada parte tem sua função no todo. Contudo, as atividades realizadas pelos atores em cada setor constituem-se dos microssistemas dentro da escola.

$\mathrm{O}$ ambiente escolar constitui-se de paisagens, pessoas, estruturas físicas, e atividades diversas realizadas no espaço escolar. De um lado, a escola apresenta ambientes físicos diversificados, tais como: a biblioteca, sala de aula, pátio formado por calçadas, hortas, jardins, portões e muros. De outro, existem as relações entre professores, coordenadores, administrador e pessoal que são mediadas pelas atividades realizadas direta ou indiretamente pelo aluno no interior da escola, bem como, as atividades extras que acontecem em ambientes externos, envolvendo o trabalho, a família e ambientes de lazer. Dentre as diversas atividades realizadas fora da escola estão, a prática de esporte, passeios, as relações com os colegas, responsabilidades com trabalho e estágio.

O contexto da escola, no qual o indivíduo se insere, ou é inserido, que se articula como agente ativo ou passivo no processo de ensino e aprendizagem é organizado e gerido por uma equipe chamada de gestão escolar. A intensidade da participação do aluno determina seu desenvolvimento pessoal e profissional, e é de responsabilidade da gestão, de toda a comunidade interna e incluindo a sociedade local.

Assim é relevante compreender como alunos e alunas do ensino técnico percebem a gestão escolar por meio das atividades realizadas, e quais as diferenças e semelhanças entre a percepção dos gêneros sobre essa temática. Nesta pesquisa verificou-se também se as ações da gestão abrangem os espaços interno e externo da escola, e buscou-se conhecer com que intensidade, esses ambientes contribuem positivamente para 0 desenvolvimento dos alunos e alunas do ensino técnico.

A problemática deste estudo configurou-se através da pergunta norteadora do projeto: De que forma os alunos e alunas do ensino técnico subsequente percebem a gestão escolar por meio das atividades que se desenvolvem no ambiente escolar?

Gestão dos microssistemas refere-se, ao gerenciamento das atividades e eventos que acontecem no ambiente da instituição e que são de responsabilidades da gestão escolar. Para verificar como se configura essa problemática, foram analisadas as percepções alunos e alunas da modalidade do ensino técnico subsequente dos cursos: mecatrônica, agronomia, controle ambiental e eletrotécnica. Este estudo apresentou uma visão da intensidade da influência do ambiente sócio escolar no desenvolvimento do processo de ensino e aprendizagem no ensino técnico. Por meio dos resultados, se pretende proporcionar aos gestores da educação uma visão de como as políticas e ações decorrentes da gestão da escola são percebidas e avaliadas pelos alunos. O diretor, juntamente com a comunidade interna da unidade de ensino, responsáveis pelas ações de aprimoramento e desenvolvimento do ensino e aprendizagem nos alunos terão maior 
possibilidade de analisar a relação entre os microssistemas e os resultados e impactos nos alunos.

O objetivo geral da pesquisa foi analisar a gestão escolar por meio das percepções de alunos e alunas do ensino técnico subsequente em uma instituição da rede oficial de ensino técnico federal em Palmas - TO. Os objetivos específicos foram: identificar o desenvolvimento humano a partir do ambiente sócio escolar e das atividades; descrever o ambiente sócio escolar a partir da percepção dos alunos do ensino técnico subsequente e equiparar as percepções de alunos e alunas com o projeto pedagógico.

O presente texto está dividido nos seguintes capítulos: a fundamentação teórica que tem como tema central, Gestão escolar como mediadora do desenvolvimento humano no ambiente sócio escolar; A metodologia, o universo da pesquisa, a técnica de análise de conteúdo e sobre os procedimentos adotados; as análises e finalmente as considerações finais da pesquisa. As siglas GF e GM são Grupo feminino e Grupo masculino.

\section{Gestão escolar como mediadora do desenvolvimento humano no ambiente sócio escolar}

Estudos mostram que ao observar o desenvolvimento humano, se considere todos os contextos, nos quais o indivíduo é inserido. As teorias genética e biológica baseiam-se em seus princípios para descrever o comportamento humano. Bronfenbrenner, Krebs e Morris estudam o desenvolvimento humano de forma dinâmica. Para eles, os contextos estão agregados no indivíduo em sua formação, apoiados em quatro níveis dinâmicos e inter-relacionados, são eles: a Pessoa, o Processo, o Contexto e o Tempo. Esses níveis são analisados por meio da teoria da abordagem ecológica, que segundo Bronfenbrenner (1977 apud Martins; Szymanski, 2004) o desenvolvimento do indivíduo é estudado considerando todos os contextos nos ambientes da escola.

A teoria dos sistemas ecológicos, criado por Bronfenbrenner e colaboradores em 1992, situa a influência dos ambientes no desenvolvimento humano. Os ambientes em que o indivíduo está inserido e a qualidade com que os microssistemas são geridos permeia a gestão os mesmos:

A interação possibilita o acesso às oportunidades de crescimento, aos momentos de estabilidade e instabilidade dos contextos nos quais as pessoas estão inseridas, as interações afetivas e as relações de poder na dinâmica interpessoal. (Bronfenbrenner, 1979/1996 apud Prati et al 2007, p. 160)

A teoria de Bronfenbrenner está relacionada com os contextos dos indivíduos vividos no estágio da adolescência. Nesse sentido, a interação entre alunos e gestão, alunas e alunos, nos diversos ambientes da escola, determina o desenvolvimento afetivo e racional de todos.

Compreende-se através de Piaget e Vygotsky que a adolescência e a puberdade, inerentes uma a outra, proporcionam transformações significativas na vida social e pessoal do indivíduo. Nesta concepção, Galvão (2001, p. 1) enfatiza que "a interação social é condição indispensável para a aprendizagem e para o desenvolvimento". A socialização se intensifica por meio da ampliação do ciclo de amizade, da maturidade mental e do envolvimento nos diversos sistemas da sociedade. Leite et al (2008, p. 2) apontam que as "desigualdades e a injustiça social se refletem profundamente na 
adolescência. De forma que, o jovem de classe mais pobre já chega à adolescência com grandes desvantagens: atravessa com muita dificuldade". A sociedade com toda sua conjuntura social, suas desigualdades, responsabilidades e necessidades, não se prepara para receber os novos membros. Estes se deparam com um mundo, que se esconde por traz das novidades, da facilidade, um sistema com ambientes distintos, socialmente habitados.

As gerações distintas compartilham os direitos $e$ obrigações, lazer $e$ responsabilidades no mesmo espaço. Esses contrastes se configuram em função das crianças e jovens desconhecerem os sistemas sociais convencionais dos adultos. Por vezes, em função das diferenças, crianças e jovens não são incluídos, nem fazem parte desses sistemas, compostos por regras.

Apesar de a escola ser um dos ambientes de socialização e maturação do indivíduo, nem sempre cumpre sua função. Os papéis são confundidos e os problemas são percebidos por quem nela convivem. As emoções do indivíduo se manifestam de acordo com sua percepção dos ambientes: "entre o indivíduo e o meio, vão se constituindo significados para as expressões, que vão passando a constituir emoções mais definidas e diferenciadas" (Galvão 2001, p. 20). Daí, a influência que a gestão dos realizados no ambiente em que esse indivíduo é inserido, pode determinar o desenvolvimento de suas emoções, bem como suas atitudes. Contudo, quanto mais estreita a relação dos microssistemas com o adolescente, melhor poderá ser o desenvolvimento dos aspectos sócio ecológicos e o desempenho desse indivíduo como pessoa e profissional.

Quanto maior consideração dos contextos vividos pelos alunos dentro e fora da escola, maior poderá ser o sucesso na elaboração e execução dos projetos, ações e atividades no ambiente escolar. Bronfenbrenner destaca o macrossistema, constituindose de toda a conjuntura que forma a sociedade, em que o indivíduo está inserido, e que intervém significativamente no seu desenvolvimento.

A escola, ainda que seja um microssistema em relação à conjuntura social mais ampla, é também, num contexto menor, um macrossistema, considerando que haja outros microssistemas dentro do ambiente escolar, tais como, os eventos, e ações particulares realizadas dentro do mesmo ambiente. Como parte do macrossistema, num contexto mais amplo, a escola tem papel crucial no processo de formação do indivíduo, que pode ser percebido pelas atividades realizadas no ambiente escolar e o envolvimento dos alunos com as mesmas. O macrossistema consiste de todo um padrão externo de microssistemas, mesossistemas e exossistemas característicos de uma determinada cultura, subcultura ou outro contexto social maior (Bronfenbrenner, 1979 apud Krebes, 2003, p. 1).

Enquanto o macrossistema é formado por todos os contextos submetidos ao aluno, tais como a escola, costumes, cultura, família, envolvimento com a sociedade, incluindo direitos e deveres na família e na sociedade como um todo, o microssistema representa cada contexto em sua particularidade. As relações entre aluno, professor e gestão são mediadas por meio de microssistemas, ou seja, as atividades, funções e inter-relações realizadas pelo indivíduo em seu meio. Um microssistema é um padrão de atividades, papéis e relações interpessoais experienciado pela pessoa em desenvolvimento em um dado ambiente, face a face, com características físicas e materiais particulares. (Krebes, 2003, p. 1). 
Sendo a escola parte do macrossistema, as atividades em geral, submetidas pelo aluno, são chamados de microssistemas. O macrossistema é um conjunto de microssistemas, é o todo formado pelas partes (microssistemas). Esses sistemas são interdependentes na gestão dos mesmos. Resta-se então à gestão escolar, à redução das lacunas entre esses sistemas, por meio da condução das atividades no ambiente escolar. A dinamização e a adequação dos sistemas no ambiente escolar podem, nesse sentido, determinar o desempenho e também, o desenvolvimento pessoal e profissional desse aluno.

A interação entre o meio e a pessoa, conforme Morais et al (2008) pode positivamente determinar as atitudes no âmbito escolar (cantina, laboratório, biblioteca e outros) no intervalo das aulas e nas atividades esportivas.

Aliados a esses ambientes, existe o ambiente imaginado individualmente, subjetivo e percebido por cada aluno individualmente ou em grupo:

Cada indivíduo percebe, reage e responde diferentemente às ações sobre o ambiente em que vive. As respostas ou manifestações daí decorrentes são resultado das percepções (individuais e coletivas), dos processos cognitivos, julgamentos e expectativas de cada pessoa. (Fernandes et al, 2003 p. 1)

Vygotsky (1989) enfatiza que a aprendizagem proporciona o desenvolvimento das habilidades psíquicas que definem o indivíduo, e o ambiente é um elemento central nesse processo. O nível de influência do ambiente depende "da apropriação que o sujeito faz dos elementos a ele transmitidos num dado ambiente cultural" (Vygotsky, 1978 apud Galvão, 2001, p. 1). As percepções manifestadas representam a concepção cognitiva do indivíduo diante do que faz ou observa no ambiente.

Para Bosquate Cohn (2004 apud Junior et al, 2010 p. 19) o espaço é movimento, no qual as formas da paisagem se juntam às pessoas, às relações sociais, pois, não existe espaço sem participação humana e sem relações sociais. Desta forma, os microssistemas, que compõem o ambiente escolar, estão interligados com os objetivos da escola, e são pensados nos planejamentos estratégicos da gestão e dos professores, nas ações que configuram o projeto pedagógico e nas políticas que visam o desenvolvimento dos alunos. Sato (2003) diz que somente a ações por si só, descritas no projeto pedagógico não garantem o alcance dos objetivos, cabe, portanto, à gestão proporcionar condições de interação entre os microssistemas e os alunos, a partir da consideração das necessidades e valores socioculturais deles.

Nesse sentido, é por meio da gestão dos sistemas, ou seja, das ações e projetos no ambiente escolar, que a gestão escolar pode ser menos excludente, em relação às ideologias clássicas que não consideravam o sujeito como pertencente a um contexto sociocultural. Ideologias clássicas correspondem ás teorias que a escola fordista se embasava para educar os indivíduos. Essas teorias não consideravam a heterogeneidade e particularidades dos indivíduos. Esse modelo de educação é ignorado diante da teoria de Bronfenbrenner. A escola preconizada por esse autor considera os valores culturais e pragmáticos locais na formulação de políticas de mudanças práticas na administração de instituições de ensino, para assim, se construir uma educação mais democrática, que tenha como princípio, atender a realidade global, mas, também a local. 
Bronfenbrenner (1989, p. 191) ressalta que o desenvolvimento humano constitui-se de um "conjunto de processos, através dos quais, as particularidades da pessoa e do ambiente interagem para produzir constância e mudança nas características da pessoa no curso de sua vida". Dai considerar essa teoria como embasamento fundamental para a gestão da educação no mundo atual.

Para Rosa (2002) os adolescentes reconhecem a grande importância de se desenvolverem atividades reais e dentro da realidade dos mesmos "através da criticidade, criatividade e afetividade dos educandos, fazendo com que a educação possa cumprir com seu papel, ou seja, fomentar o desenvolvimento do ser humano de maneira integral". Em razão disto, enfatiza-se a necessidade da gestão escolar ter como um dos seus objetivos, proporcionar oportunidades ao aluno de desenvolver a criatividade e expressarse por meio das atividades realizadas na escola.

\section{Projetos pedagógicos e a gestão escolar democrática}

Ao considerar a importância do ambiente no desenvolvimento da pessoa, percebido na teoria dos sistemas ecológicos de Bronfenbrenner, os projetos pedagógicos, numa gestão democrática, são pensados, planejados, dialogado com a sociedade e aplicados, com o objetivo de proporcionar a formação e o desenvolvimento do alunado. A escola, por meio de seus microssistemas e o meio sociocultural do aluno, pode proporcionar o diálogo como uma maneira de inter-relacionar com os microssistemas.

As políticas educacionais, no contexto contemporâneo indicam a importância de contemplar as realidades e especificidades locais de cada região, estado e município, por meio dos projetos pedagógicos das escolas. Para Dourado (2007), a educação é uma prática social constituída de relações entre o homem, escola, bem estar da sociedade, cultura e economia. A gestão escolar tem natureza própria, é muito mais do que uma instituição social ou empresa privada, sua natureza não se organiza por meio de ideias construídas de origem hegemônicas, como as políticas e programas de cunho financeiro. A autonomia dada à gestão escolar e a pedagógica não se baseia, nem se confunde, muito menos se limita à autonomia financeira. A gestão escolar é todo o sistema de ensino e aprendizagem no âmbito macro adotado na unidade escolar. Gestão e autonomia podem-se consolidar na execução de políticas de ações que atendam às necessidades da sociedade local, pois, supõe-se que a escola conhece as deficiências locais, e elabora sua proposta pedagógica a partir dessas referências, bem como decidi sobre a aplicação dos recursos (Mello e Silva, 1991, p. 10).

Nessa perspectiva é que Bronfenbrenner pontua que a proposta de ação a qual chama de processo proximal é que defende a importância do ambiente onde ocorrem os cinco aspectos desenhados por ele, em que se desenvolvem as potencialidades e habilidades da pessoa.

No espaço da escola, ensino e aprendizagem são compartilhados, como acrescenta a teoria de Bronfenbrenner, o que há é uma troca de conhecimentos, para isso, concorrem todos os agentes concretos (professores, gestão, alunos e a infraestrutura) e abstratos (microssistemas em que os alunos são protagonistas, e ainda aqueles que direta ou indiretamente os influenciam).

Respeitabilidade e ética se constroem por meio de estratégias harmônicas e de relações afetivas criando um vínculo positivo para o desenvolvimento dos alunos. Para 
Vieira (2007), o sucesso da gestão está na competência de ensinar a comunidade de alunos. Então, pode-se inferir que a gestão escolar tem a responsabilidade de promover a interação dos microssistemas com os alunos. A escola, nesse sentido, se configura como um espaço próprio para difusão do saber, e deve convergir para a aprendizagem daqueles a quem ela foi criada, sejam crianças, desde a mais tenra idade, sejam jovens e adultos. A necessidade de pensar a educação do indivíduo na geração atual, considerando as realidades que o cerca, é uma ideia que também é defendida por André (1995). Para ele, conhecer uma escola é observar tudo o que acontece no ambiente escolar, "identificando as estruturas de poder e os modos de organização do trabalho escolar, analisando a dinâmica de cada sujeito nesse complexo interacional" (Andre, 1995 apud Veiga, 2008, p. 10).

Marinho, Araújo e Almeida (2005) apontam que algumas escolas se sustentam na concepção de que nada pode impedir maus processos de desenvolvimento e transformação humana, por isso, essas escolas "se utilizam de possibilidades oriundas das rachaduras do sistema as quais podem libertar o indivíduo da força e intenção opressora" (Cavalcanti, 2009, p. 31). Cabe, à gestão, identificar os problemas e procurar a correção ou minimização deles.

A gestão, que consegue gerenciar melhor as ações, os projetos e atividades, de acordo com a realidade dos alunos e do ambiente escolar, poderá contribuir positivamente ao desenvolvimento humano e reconhecer as especificidades dos alunos, para então, driblar os problemas e alcançar o objetivo final que é o sucesso do aluno. Para isso, o que conduz esse processo é o modelo de gestão e educação adotado na escola. Essa qualidade depende da democratização da gestão que começa com a construção do projeto pedagógico.

Coelho e Linhares (2008, p. 1) apontam a necessidade de mudanças de atitude do diretor, afim de que o mesmo faça reconhecer sua importância na organização da escola, e esta, a formação do aluno como cidadão ativo nas decisões de nível pessoal, profissional, e da sociedade. "O gestor não decide de forma arbitrária pela escola em que atua, mas convida a comunidade para a elaboração do projeto político-pedagógico" (Ibid., p. 1). A gestão democrática, nesse sentido, detém o poder maior na promoção de uma escola, cujo ambiente atenda as necessidades da comunidade local. Lück (1990, p. 5) destaca que "o gestor deve ter a habilidade de influenciar o ambiente que depende em grande parte, da qualidade e do clima escolar, do desempenho do seu pessoal e da qualidade do processo ensino-aprendizagem". O ambiente e os microssistemas são, portanto, organizados de acordo com os objetivos propostos em um projeto pedagógico participativo. Para isso, a gestão é que pode proporcionar um ambiente propício, em que, lazer, partilhas, debates, reflexões sobre temas específicos se integram, com confraternização e coesão, numa relação harmônica entre os agentes da comunidade (ibid, p. 6).

O projeto pedagógico descreve o modelo de educação ideal adotado pela gestão escolar local. Para Gerir (2003, p. 22), "um projeto prova ser bom se for suficientemente completo para exigir uma variedade de respostas diferentes dos alunos e permitir, a cada um, trazer uma contribuição que lhe seja própria e característica". Para o mesmo autor, são as respostas que vão apontar o resultado do projeto, seja positivo ou negativo. Deve contemplar ações concretas que atendam os anseios e necessidades, a fim de solucionar 
os problemas reais existentes. É através do projeto pedagógico que se constrói uma gestão participativa. Esta passa a ser uma oportunidade de participação da comunidade, nas decisões da escola: "As diretrizes organizacionais nortearão a atuação dos educadores, servindo como uma forma de a comunidade opinar sobre os elementos que são relevantes para a implementação de um ensino de qualidade" (Zanlorenço; Schnekenberg, 2008, p. 2).

A participação é apontada por Libâneo (2007) como uma forma de assegurar a gestão democrática, o envolvimento dos agentes da escola, em todas as decisões. Portanto, participação ocorre com o envolvimento da comunidade formada por pais, representações sindicais, órgãos governamentais, não governamentais, e agentes locais em geral. A participação é uma forma de consultar e ouvir a comunidade local, antes de tomar decisões de seu interesse ou que envolvam o processo educativo. É por meio das ações e projetos aliados aos recursos tecnológicos modernos e a infraestrutura do ambiente, que se identificam e desenvolvem as potencialidades e, ainda, solucionam os problemas.

\section{Estrutura da Gestão da Educação dos Institutos Federais de Educação, Ciência e Tecnologia}

A educação profissional no Brasil é regulamentada pela Lei de Diretrizes e Bases da Educação. De acordo com o art. 42, "as escolas técnicas e profissionais, além dos seus cursos regulares, oferecerão cursos especiais, abertos à comunidade, condicionados à matrícula e à capacidade de aproveitamento e não necessariamente ao nível de escolaridade". O ensino profissional é oferecido por diversas instituições, além das escolas técnicas federais. O Instituto de Educação, Ciência e Tecnologia do Estado do Tocantins - IFTO - teve sua criação oficializada pela lei n. 11.892, de 29 de dezembro de 2008. Por essa lei, as escolas técnicas federais por opção, puderam migrar para esse novo sistema federal de ensino. Art. 10 "Fica instituída, no âmbito do sistema federal de ensino, a Rede Federal de Educação Profissional, Científica e Tecnológica, vinculada ao Ministério da Educação."2

O ensino profissional no IFTO é ofertado por meio das modalidades do ensino técnico integrado ao ensino médio, ensino técnico subsequente, e ensino superior. Tem sua gestão estruturada diferentemente das escolas de ensino médio regulares. De acordo com o "art. 9, cada Instituto Federal é organizado em estrutura multicampi, com proposta orçamentária anual identificada para cada campus e a reitoria, exceto no que diz respeito a pessoal, encargos sociais e benefícios aos servidores." Os cursos técnicos subsequentes têm duração de dois anos.

Apesar de a educação profissional ter um foco pré-estabelecido, que é a formação de mão de obra específica, possui disciplinas base da educação regular, não exclui a preocupação com a formação pessoal, logo, não se pode afirmar que o modelo de gestão, nessa modalidade de ensino, é específico, ou menos relevante, ou que pode ser menos democrático, mas que todas as possibilidades podem ser oportunizadas ao educando com o objetivo de crescimento e desenvolvimento integral do mesmo.

O processo de decisão dos novos cursos ocorre por meio de resultados de pesquisas de demanda local, via questionários, que são respondidos pelos comerciantes

2 Diário Oficial da União, Seção 1- Ano CXLV No- 253 Brasília - DF, terça-feira, 30 de dezembro de 2008.

\begin{tabular}{|l|l|l|l|l|l|}
\hline Regae: Rev. Gest. Aval. Educ. & Santa Maria & v. 2 & n. 3 & Jan./jun. 2013 & p. $45-64$
\end{tabular}


e lojistas locais, incluindo os funcionários dos comércios e os alunos matriculados nos diversos cursos da instituição. A construção dos projetos tem a participação do colegiado por meio de discussões e colaborações escritas via correio eletrônico e reuniões presenciais direcionadas a esse fim. $O$ que se percebe, apesar de todo o processo participativo por meio dos atores da gestão, na construção dos projetos dos cursos, é que ocorre com muita frequência a necessidade de mudanças do projeto original.

Para todos os cursos, o estágio é realizado por meio de projetos na própria unidade de ensino, em empresas e em outras organizações, em unidades de aplicação ou em empresas pedagógicas; além de atividades de extensão. Os alunos trabalhadores, quando inseridos em atividades produtivas relacionadas à área profissional do curso, poderão ter essa efetiva prática profissional reconhecida, para fins de cumprimento da carga horária de Estágio Supervisionado, a partir da avaliação do relatório a ser apresentado. Há acompanhamento, controle e avaliação em todos os estágios.

Os laboratórios são equipados com equipamentos, materiais, componentes, ferramentas, e horários diversos para realização das aulas práticas. Além dos laboratórios, os alunos dividem um ambiente com espaços e departamentos comuns a todos dentro da unidade de ensino, cujo tamanho e capacidade são mostrados a seguir: duas quadras poliesportivas descobertas; um campo de futebol gramado; ginásio de esportes; biblioteca; quatro laboratórios de informática; auditório para 200 pessoas; auditório para 80 pessoas.

\section{Aspectos metodológicos que conduziram o processo da pesquisa}

Por ser uma pesquisa qualitativa estruturada com base aos encaminhamentos metodológicos provenientes da pesquisa etnográfica. Realizar pesquisa qualitativa etnográfica implica ao pesquisador "participar, observar, conversar com aqueles que se dispuserem e conservar, o máximo possível, essa experiência por escrito". Para isso, deve haver uma relação de confiança entre o pesquisador etnográfico e o sujeito. Essa relação de confiança se configura durante todo o discurso, desde a seleção dos participantes: "nesse sentido, tal escolha é etapa da maior importância na realização do estudo de caso etnográfico" (Viégas, 2007, p. 110).

O objeto pesquisado é construído a partir da concepção que surge da relação íntima do pesquisador com os sujeitos envolvidos na investigação. São características da pesquisa etnográfica em educação: compreensão e descrição dos significados e as experiências atribuídas pelos próprios sujeitos; interpretação de todas as situações advindas de concepções contrárias dos sujeitos e sua própria, para construir uma realidade plural, ao considerar as adversidades e diversidades constatadas na pesquisa; usar de questionamentos (como e por que) para se inserir no contexto do objeto.

$\mathrm{Na}$ pesquisa etnográfica, o pesquisador reflete sua posição, os instrumentos utilizados na coleta de dados, a metodologia e, quando possível e necessário, adiciona ou elimina elementos no processo da pesquisa. Reflete, também, sobre o planejamento durante as etapas da pesquisa. Para Viégas (2007, p. 108) "toda descrição envolve, necessariamente, uma conceituação do objeto (seja ela implícita ou explícita), a ideia de mera descrição que seja desprovida de teoria torna-se insustentável". A pesquisa etnográfica é executada apenas com análise qualitativa, pela complexidade da pesquisa e por tornar possíveis todas às características. Conforme esse autor, na análise etnográfica, 
as categorias decorrem do próprio processo de investigação. Não visa, portanto, confirmar hipóteses; ao contrário, estas são aventadas baseando-se na inter-relação de muitas peças singulares do campo.

A educação se apresenta como um espaço de grande quantidade de pesquisas possíveis, por envolver seres humanos heterogêneos, de culturas, realidades e contextos diversificados, ao se tratar de professores, alunos, gestores e da sociedade em geral.

O contexto escolar é palco de reflexões, debates de problemas complexos que, muitas vezes, não se resolvem apenas nos gestores, mas os professores, pessoal, alunos e sociedade participam na investigação dos problemas. Daí o campo propício para pesquisas qualitativas. A opção por essa abordagem se dá pelo objetivo da pesquisa, ao se tratar especificamente de um grupo de alunos e alunas no ambiente escolar. A descrição de expressão subjetiva dos indivíduos a serem pesquisados sobre os fenômenos que os cercam, requer um efetivo cuidado entre o pesquisador e os entrevistados. Para Chizzotti (2006, p. 28) a pesquisa qualitativa "implica uma partilha densa com pessoas, fatos e locais que constituem objetos de pesquisa, para extrair desse convívio os significados visíveis e latentes, e que somente são perceptíveis a uma atenção sensível". Portanto, essa abordagem vem corresponder às características desta pesquisa, que é a de analisar as percepções de alunos quanto o ambiente escolar.

A pesquisa foi realizada em um dos campi do Instituto Federal de Educação, Ciência e Tecnologia e fizeram parte dela, de forma voluntária, 20 alunos do segundo ano do ensino técnico subsequente de uma unidade de ensino técnico da cidade de Palmas - TO. Os istrumentos utilizados para a coleta de dados foram entrevista, a partir de um questionário de perguntas estruturadas, semiestruturadas e não estruturadas, e observação in loco.

Como critério de seleção dos entrevistados foi realizado sorteio nas turmas do segundo e terceiro módulo, de forma que vinte alunos foram selecionados e devido à dificuldade de encontrar um número igual de gêneros diferentes, a entrevista se deu com dez alunos e 11 alunas. Depois de informados sobre os conceitos de microssistemas, gestão e ambiente, cada aluno recebeu um questionário escrito com um roteiro de perguntas à cerca do ambiente sócio escolar, das atividades/ações/projetos e da gestão escolar.

Realizou-se um relatório de observação nas visitas realizadas conforme calendário da escola no período de abril e maio, para Identificar as atividades realizadas regularmente e descrever a relação entre os alunos, os microssistemas e ambientes físicos da escola.

A abordagem qualitativa foi adotada para análise das informações coletadas no relatório de observação, relatório de entrevista e relatório de atividades registradas no projeto pedagógico da escola para o primeiro semestre de 2011. Por possibilitar interpretações múltiplas das mensagens e considerar o contexto dos sujeitos entrevistados, técnicas da análise de conteúdo foram usadas na interpretação das informações coletadas nas entrevistas. 


\section{Gestão do ambiente sócio-escolar na percepção do gênero feminino e masculino}

As análises no geral mostram que os estudantes apreciam de forma positiva a gestão local, incluindo todos os espaços frequentados como agradáveis. "Sim. Pois é muito agradável, limpo e organizado, muito conscientizado em relação ao meio ambiente" (GM). Destaque para a justificativa das alunas ao referirem-se à qualidade do ensino e a sensação de liberdade, o que pode ser proporcionada pela harmonia ligada a arborização local. Esse fator levou as alunas descreverem a instituição como a segunda casa. No aspecto estrutural, estão satisfeitas com o que é oferecido pela instituição: "Sim. É um ambiente grande e a estrutura da instituição nós fornece o que precisamos".

Todos os alunos reconhecem a arborização como a beleza e o bem estar local e estimulador da aprendizagem. $O$ não funcionamento do ar condicionado em algumas salas foi o único fator negativo apontado.

A concepção positiva do ambiente é configurada também na descrição sobre o ambiente. Quase todos os estudantes descreveram o ambiente por meio das atividades de lazer e a arborização:

Aqui dispomos de quadra, piscinas, muitas arvores é um bom lugar para estudar (GM). Agradável, pois os alunos tem um contato direto com a natureza (GF 13). Um lugar com muito verde, salas amplas, quadra, campo, piscina, muito bonito (GF);Um ambiente agradável e com muitos recursos (GF).

As percepções dos alunos e alunas têm por base o lazer através das atividades esportivas e o conforto na sala de aula. Esse fator vem ao encontro da afirmação de Prati et al $(2007,162)$ ) "desenvolvimento humano ocorre através de ampliações e aproximações entre a pessoa e os diversos elementos do contexto que se interagem mutuamente de forma não linear e dinâmica, alterando-se qualitativamente ao longo do tempo". Para esse autor a gestão dos microssistemas (atividades e eventos) que ocorrem no ambiente escolar influencia o desenvolvimento dos mesmos, pois, se preocupa com a qualidade das atividades, projetos e eventos desenvolvidos na instituição.

O interesse pelo lazer foi notado nas percepções sobre as atividades regulares do cotidiano fora da instituição. Os alunos exercem atividades diversas, tais como, viajar, jogar futebol, vídeo game, estudar e socialização com amigos. A princípio não citaram o trabalho, ou qualquer atividade que exigem maiores responsabilidades.

A vinculação daquilo que fazem em casa com o que observam na unidade escolar vai ao encontro da teoria de Bronfenbrenner (1989) ao defender que se pense nos valores culturais e pragmáticos locais ao formular políticas de mudanças na gestão escolar, no sentido de se construir uma educação democrática que atenda as realidades locais. Nesse sentido, todos os contextos vividos pelos alunos (na sociedade e na escola) se articulam como agente do processo. Assim, a intensidade do envolvimento do aluno nas atividades e nos eventos em geral pode determinar sua influência no desenvolvimento do mesmo. O mesmo autor salienta que o desenvolvimento humano constitui-se de um "conjunto de processos em que a particularidade da pessoa se interage com as particularidades do ambiente" (Bronfenbrenner, 1989, p. 191). Este fator proporciona ao indivíduo transformações diversas significantes na formação e no desenvolvimento pessoal e profissional do indivíduo. 
As alunas demonstraram ter maior responsabilidade e preocupação ao relacionar a realidade da vida social com o desempenho na escola. Apesar de os dois grupos terem a mesma média de idade, o grupo das alunas apresentou maior maturidade intelectual nas respostas que descrevem o interesse dos alunos e alunas.

Notou-se também, que os alunos conhecem a maioria dos espaços da instituição que estudam. As coordenações e laboratórios dos cursos que estão ligadas diretamente e departamentos de outros cursos na unidade escolar, além de outros espaços, como a diretoria, transporte, serviço social e etc. Notou-se que os espaços citados estão entre os citados como mais visitados e mais frequentados, porém, somente os alunos citaram pátio próximo à reprografia, biblioteca, academia e o refeitório.

Três percepções comuns entre os gêneros foram notadas: ir ao laboratório, participar das aulas práticas e do esporte dentro do ambiente da instituição. A gestão proporciona dentro do ambiente escolar, ações que fazem com que os alunos conheçam todos os espaços locais. Observou-se que além das aulas realizadas nos laboratórios dos cursos, os eventos extras e as atividades que acontecem nos auditórios, as aulas de natação e disponibilização de professores de esportes diversos na academia, que permitem a preparação dos alunos à participação de torneios a nível interno, local, regional e nacional, são estratégias da gestão que fazem com que os alunos frequentem os diversos ambientes na unidade de ensino.

Ambos os grupos apontaram espaços comuns como o laboratório, lanchonete, e ginásio poliesportivo. Embora não haja nenhuma semelhança entre os gêneros, neste aspecto, alunas e alunos compartilham visitas a alguns departamentos específicos, porém, o centro de línguas, em ocorrem cursos extras, não foi citado entre os lugares frequentados em função de estar muito tempo fechado.

Somente os auditórios dos blocos não foram percebidos a princípio, mas, sim, ao longo da entrevista, pelo grupo masculino ao falar do espaço de menor interesse em frequentar. Notou-se que os alunos percebem os departamentos presentes no ambiente local, conforme apresentados no projeto pedagógico. Dai, se confirma a teoria de Bronfenbrenner (1979/1996 apud Prati et al, 2007, p. 160), de que a interação social com outros indivíduos nos diversos ambientes em que estão direto e indiretamente inseridos, determina seu desenvolvimento afetivo e racional.

Ambos os gêneros praticam atividades de lazer fora da instituição, tais como, o futsal, futebol society, a corrida, práticas de esporte, caminhada e ciclismo, também, manifestam interesse maior, na prática desses esportes na unidade escolar, disponibilizados pela gestão e facilitados pela estrutura local.

\section{Pontos distintos entre alunas e alunos na afetividade com o ambiente local}

As alunas citaram mais razões que os alunos justificar o fato de gostarem do ambiente escolar, sete elementos diferentes das do grupo masculino: a qualidade do ensino, a sensação de liberdade proporcionada pelo ambiente, arborização local e considera o ambiente, a segunda casa, bem como a dimensão da estrutura da instituição, ao descrever os departamentos, a área livre existente, e finalmente a organização local. Contudo, estão satisfeitas com o que é oferecido pela instituição. Elas foram muito mais detalhistas que o grupo masculino, ao abranger aspectos de caráter afetivo (liberdade, segunda casa) e também, aspectos objetivos (a organização e arborização). Este fator vai 
ao encontro da observação de Galvão (2001, p. 20) de que "entre o indivíduo e o meio, vão se constituindo significados para as expressões, que vão passando a constituir emoções mais definidas e diferenciadas." Notou-se que a satisfação das alunas não é aleatória, mas que é fundamentada no que observam e o sentimento proporcionado pelas características do ambiente local. "Sim. É um ambiente grande e a estrutura da instituição nos fornece o que precisamos."

As alunas perceberam cinco diferentes pontos em comparação aos alunos, em relação ao ambiente: a natureza, ambiente agradável, os recursos suficientes na configuração da qualidade do ambiente, a cantina e o fato de ser uma instituição que está em fase de crescimento. A satisfação com o ambiente e microssistemas - atividades e eventos realizados nos ambientes do campus - nos leva a afirmar que os alunos concordam de alguma forma com o trabalho da gestão em relação aos recursos disponibilizados.

Não obstante, as alunas também citaram pontos a melhorar: a falta de cuidado com a organização (limpeza) do espaço externo à unidade de ensino. Somente as alunas percebem o contraste entre a organização do ambiente interno com a desorganização do ambiente externo: "paisagem de fora um pouco desleixada por causa do mato que dá um aspecto feio" (GF).

O ambiente fora da escola é elemento constitutivo do macrossistema e dele também depende o desenvolvimento do interior da escola. Bronfenbrenner enfatiza a importância do macrossistema, ao apontar que intervêm de forma significativa no desenvolvimento do indivíduo, determinando-o. E a escola, por meio dos microssistemas, pode contribuir no desenvolvimento do indivíduo por estreitar a relação entre os alunos através de trabalhos da gestão.

Conforme Vygotsky (1989), cada indivíduo percebe, reage e responde diferentemente às ações sobre 0 ambiente em que vive. $O$ autor enfatiza que a aprendizagem proporciona o desenvolvimento das habilidades psíquicas que definem 0 indivíduo. Por esta razão, a inserção do aluno em diversos contextos (dentro e fora da instituição) por meio de atividades de aprendizagem, pode contribuir no desenvolvimento das habilidades desse indivíduo. Foi observado que, as alunas e não os alunos têm a cantina/lanchonete como espaço que mais gostam de frequentar. Todas as atividades que gostam de realizar, visitas técnicas, pesquisas, aulas nos laboratórios de microbiologia e físico-química, assistir vídeos e seminários, estágios e projetos integrados, as visitas técnicas e aulas nos laboratórios são as mais citadas. Como caraterísticas dessas atividades foi citada a praticidade proporcionada por elas como fator que atrai com mais eficiência que a teoria. Ao mesmo tempo, é a oportunidade de executar a teoria estudada.

Foram detectadas seis diferentes atividades realizadas fora de instituição, citadas pelas alunas: acampamento, vôlei, clube, caminhada e ciclismo, trabalhos educativos em escolas públicas e exercícios físicos, apenas, uma afirmou não realizar qualquer atividade fora do instituto. As alunas que em comparação aos alunos, estão mais diretamente ligadas às atividades relacionadas ao curso. Embora citassem as atividades de lazer dentro da unidade de ensino, o comprometimento com atividades educativas fora da instituição mostra que as alunas estão, com maior frequência, conectadas às atividades que tem alguma relação com o curso que realizam. O mesmo em relação à participação nos cursos que se estendem a ambientes fora da instituição. $O$ fato de as alunas 
afirmarem que participam do estágio, referindo-se às aulas ministradas à comunidade externa, e também das pesquisas, visitas técnicas e atividades ambientais, demonstra que essas conhecem todos os projetos e atividades dos cursos que ocorrem nos ambientes externos.

Os dois gêneros têm uma relação bem afetiva com os espaços na instituição, pois, demonstraram conhecer não somente aqueles que são diretamente ligados aos seus cursos - indústria, meio ambiente, estágio, eventos -, mas também de outros cursos, como laboratório de química e informática. A familiaridade com ambos os espaços pode ser facilitado pela relação com outros alunos. Fator este, considerado positivo ao entender que a gestão tem proporcionado a interação entre os alunos.

É ratificada desta forma a posição de Mello e Silva, de que, a escola tem autonomia para elaborar políticas internas, de forma que, o projeto pedagógico contemple a cultura, costumes e valores locais, e que atendam às necessidades da comunidade escolar, pois, a gestão escolar conhece os problemas e necessidades, e pode em função disto, melhor decidir sobre a aplicação dos recursos.

A autonomia da gestão pode ser utilizada para mesclar os interesses da escola com as ações que atendam o interesse dos alunos e assim, poder desenvolver as capacidades individuais: "a importância da presença simultânea de cinco aspectos para que se estabeleça um processo proximal: a pessoa deve estar engajada em uma atividade; esta atividade deve acontecer em uma base relativamente regular" (Prati et al., 2007, p. 160). Portanto, as manifestações subjetivas, tais como, a imaginação e motivações do indivíduo dependem da relação com os elementos externos a ele, como exemplo, a comunidade local, o trabalho e a família.

\section{A gestão escolar e suas responsabilidades na concepção dos alunos}

A concepção dos grupos sobre gestão escolar é semelhante entre os gêneros, pois, ambos os grupos sintetizam a gestão como o ato de coordenar, administrar e controlar as atividades e eventos da instituição. $70 \%$ dos entrevistados já ouviram sobre gestão e a aliam, como sendo, uma ação semelhante ao de administrar, como foi observado nas respostas: "Coordenação, pessoas designadas a conduzir da forma mais adequada; Administrar e Controla atividades num determinado meio; É o ato de gerenciar uma escola, de forma hierarquizada começando da atitude do gestor até os alunos" (GF e GM).

O que o aluno realiza na unidade de ensino, e o perfil do ambiente escolar são descritos e estão interligados com os objetivos da escola, pois, eles são pensados nos planejamentos estratégicos da gestão e dos professores nas ações que configuram o projeto pedagógico por meio das políticas que visam o desenvolvimento dos alunos.

Quanto às responsabilidades da equipe de gestão, houve semelhanças nos dois grupos. Em comum, citaram os eventos, palestras, cursos e projetos de extensão que ocorrem na instituição, como parte da responsabilidade da gestão. "Coordenação, pessoas designadas a conduzir da forma mais adequada; administrar e controlar atividades num determinado meio; é o ato de gerenciar uma escola, de forma hierarquizada começando pela atitude do gestor até os alunos" (GF e GM).

Para os alunos e alunas, as aulas não fazem parte das responsabilidades da gestão, pois, os entrevistados não fizeram menção às aulas em sala de aula, nas respostas sobre 
gestão. Relacionaram a gestão com os eventos extracurriculares, que são os cursos no centro de língua e as visitas técnicas.

A concepção de gestão está também na percepção dos lugares mais visitados pelos alunos, que são: a biblioteca, ginásio, laboratórios de informática e a quadra, relatados pelos dois grupos, demonstrando que as alunas praticam esportes na mesma intensidade que os alunos. A lanchonete foi citada por apenas um dos alunos entre os lugares mais frequentados.

Todos citaram os eventos na instituição e administração local. Contudo, os sujeitos não possuem conhecimento detalhado quanto à divisão das responsabilidades na instituição. Ao ligarem gestão com administração, notou-se que os alunos são conscientes dos determinados poderes e da gestão responsável pela organização local: "É o ato de gerenciar uma escola, de forma hierarquizada" (GM).

\section{Percepções dos alunos sobre os microssistemas}

As entrevistas revelam que as atividades esportivas no instituto prevalecem como as preferidas dos alunos e alunas, em seguida, as aulas práticas. Não houve um consenso, mas, uma grande variedade de diferenças no gosto dos sujeitos em relação do que fazem fora da unidade de ensino, mais especificamente, em relação aos cursos.

Embora, a palavra estudar apareceu uma vez nas respostas de ambos os grupos, não se configura falta de compromisso com as aulas e o curso em geral, nem tão menos, com o desenvolvimento profissional, pois, dentre os lugares que mais frequentam estão os laboratórios e a biblioteca.

Notou-se, que apesar dos projetos pedagógicos apontarem os estágios a partir do segundo módulo, um total de onze alunos (4 alunos e 7 mulheres), informaram não ter realizado essa atividade, os entrevistados apresentaram-se conscientes das vantagens e benefícios de participar do estágio, a ponto de aponta-lo entre aquelas que gostariam de realizar. O estágio foi lembrado pelas alunas, como atividades do curso que se estendem a outros ambientes, enquanto nenhuma atividade distinta foi apresentada pelo gênero masculino. Observou-se que as alunas ministram aulas sobre educação ambiental, pesquisam, e realizam visitas técnicas e atividades ambientais.

Os cursos, congressos, palestras realizadas paralelamente às aulas são, na maioria, previstos nas ações definidas pela gestão democrática que adota um modelo democrático na condução desses microssistemas. Fator este, que permite que os alunos absorvam o máximo da interação com o ambiente e das atividades que realizam na instituição. Dai reafirmar o apontamento de Ferreira de que a gestão escolar é a "garantia de qualidade do processo de formação humana expressa no projeto pedagógico que possibilitará ao educando crescer e, através dos conteúdos do ensino" (Ferreira, 2006, p. 309).

Conforme, o projeto pedagógico, o estágio profissional prepara o aluno para o exercício profissional por meio da vivência de situações concretas de trabalho. Para todos os cursos o estágio é realizado por meio de projetos na própria unidade de ensino, em empresas privadas, em órgãos públicos e organizações locais, e também nas unidades de aplicação ou em empresas pedagógicas, além de atividades de extensão.

Dentre as atividades realizadas pelos sujeitos que disseram sim, estão as visitas técnicas, instrutores em núcleos, cursos de curta duração, além dos estágios: "Sim. Sou 
instrutora dos cursos oferecidos pelo núcleo de pesca, em parceria com IFTO, em outra cidade: Marianópolis" (GF).

As visitas técnicas e estágios são as atividades relacionadas que mais atraem a atenção dos alunos. Conforme, relatório de observação, há uma constante preocupação da unidade de ensino, em conseguir empresas para atender as demandas dos cursos. Isto se dá, também, pela grande quantidade de instituições de ensino na cidade, que ofertam cursos profissionalizantes, cujos projetos incluem estágio, como obrigatoriedade.

O campus, como estabelecido em lei, segue às determinações legislativas e proporciona a formação completa ao aluno por meio do ensino teórico, aulas regulares, e prático - estágios, projeto de extensão, visitas técnicas e laboratórios - ao cumprir os objetivos da criação dos cursos profissionalizantes. Notou-se que apesar de ser comum aos grupos, o interesse em realizar essas atividades, ainda não foram proporcionados a todos os componentes dos grupos: visitas técnicas, aulas de campo, estágios e curso de inglês, espanhol e natação. Conforme os entrevistados, somente quatro alunas e quatro alunos tiveram oportunidades de realizar aquelas atividades, restando então, mais de sessenta por cento, dentre os entrevistados, que até o momento da entrevista, não tiveram a oportunidade de realiza-las. Os grupos manifestam o interesse na formação, desenvolvimento profissional e buscam desta forma, formação em cursos de curto prazo oferecido pela instituição. À gestão escolar é dada a gestão da oferta dessas atividades, para que se atenda a legislação e as determinações do projeto pedagógico.

As atividades extracurriculares têm papel fundamental na conquista dos alunos, esse interesse é manifestado por grande parte dos sujeitos na realização da formação continuada. Para Galvão "a interação social é condição indispensável para a aprendizagem e para o desenvolvimento" (Galvão, 2001, p. 1). A socialização se intensifica por meio da ampliação do ciclo de amizade, da maturidade mental e envolvimento nos diversos sistemas da sociedade. Os eventos extracurriculares contribuem na relação social e afetiva entre aluno e ambiente sócio escolar.

Sobre as atividades que gostariam de participar, as visitas técnicas ocuparam o topo das citações de ambos os gêneros, sete sujeitos ao todo. Seis alunas e três alunos citaram os cursos complementares. As atividades esportivas e de lazer apareceram poucas vezes, isto é, duas vezes nas respostas dos alunos, e apenas, uma aluna citou atividades de lazer. Para Lück (1990, p. 5) a gestão escolar detém nas entre linhas de sua função a preparação, o cuidado com o ambiente, em que é executado o projeto pedagógico. A qualidade do ambiente escolar, dos microssistemas, do clima escolar e do desempenho dos alunos depende da logística da gestão com um todo. Essa relação entre esses papéis determina os resultados manifestados pelos alunos, seja enquanto indivíduo no ambiente da escola, e ainda com a aprendizagem. Para tanto, a harmonização entre a escola (ambiente), o projeto pedagógico e os alunos dependem da integração entre lazer, aprendizagem e propósitos da escola por meio dos microssistemas (Coelho Linhares, 2008, p. 6).

\section{Considerações finais}

O contexto das análises das percepções dos alunos do ensino técnico subsequente remete-nos a reflexão de pontos relevantes quanto à gestão dos microssistemas nessa modalidade de ensino. 
Primeiro, que embora, tenha ficado evidente nas respostas dos alunos e alunas, a insatisfação com a organização das atividades realizadas na instituição, notou-se no geral, que responderam positivamente sobre o conjunto dos microssistemas realizados no ambiente da instituição.

Segundo, que ainda que, os entrevistados estejam se inserindo nas atividades de estágio, a partir do módulo em que estão, segundo e terceiro módulos, percebe-se a falta de equidade da participação nas atividades extracurriculares. Este fator demonstra que há problemas na gestão dessas atividades. As análises apontam que o número de vagas de estágio e nos cursos extracurriculares, cursos extras do Centro de Línguas e em outros departamentos, ofertados pela gestão aos alunos e alunas não atende à demanda dos cursos.

Dos 20 alunos pesquisados, a maioria mostrou-se convincente do desenvolvimento de suas capacidades e habilidades, pessoais e profissionais. A utilização desse espaço não é proporcionada de forma igualitária a ambos os gêneros. Enquanto o projeto pedagógico e a observação in loco descrevem a existência de um auditório em cada bloco de salas, as alunas não tiveram, mesmo com um ano de curso, oportunidade de participar das atividades realizadas nos auditórios. Há interesse por parte dos alunos nos cursos complementares promovidos pela instituição, porém, somente as alunas conseguiram oportunidades nas atividades ofertadas.

O instituto oferece cursos à comunidade externa, como estabelecido no projeto pedagógico, e determinado da Lei de Diretrizes e Bases da Educação, no entanto, não é suficiente para atender a demanda. Este fator pode estar sendo comprometido pela inatividade do Centro de Línguas, espaço criado para ofertar cursos de línguas e outros. O não funcionamento justifica a insatisfação dos alunos entrevistados, no quesito da participação nas atividades extracurriculares.

Ao analisar a atuação da gestão na promoção de atividades esportivas, tanto nas entrevistas quanto na observação in loco, constatou-se a distribuição proporcional desses recursos esportivos, tais como, academia, piscina, centro esportivo com quadra e campos de futebol society, todos disponíveis no ambiente local. Esses espaços são utilizados pelos alunos. Nesse aspecto, a satisfação dos alunos foi unânime. Vale analisar que basear o conceito de gestão dos microssistemas, bem como, sua avaliação, a partir das atividades esportivas e de lazer, contempla o papel dos institutos, determinado na lei 11.892 de 29 de dezembro de 2008, porém, apenas esse ponto não corresponde ou resume todas as responsabilidades da gestão na promoção e organização dos microssistemas para a formação profissional e humana do aluno.

Além das atividades de lazer, as aulas, eventos em geral, estágios, atividades extracurriculares, os recursos tecnológicos e as mídias em geral, incluindo tudo o que acontece no ambiente da instituição são de responsabilidade da gestão escolar. Desta forma, o fato de, as atividades de lazer, serem o único fator apontado ao avaliar a gestão local como positiva, questiona-se a pouca relevância observada sobre todos os outros elementos que também constituem responsabilidades da gestão. A razão pode ser a pouca maturidade crítica dos alunos em perceber os aspectos importantes no desenvolvimento humano dos mesmos. Fator este, que pode ser pensado, planejado e trabalhado pela gestão, nos projetos pedagógicos, proporcionados, atividades que possam desenvolver a capacidade cognitiva dos alunos, para melhor perceberem 0 
mundo em volta e, consequentemente, melhor interagir com os microssistemas no ambiente escolar.

Por meio das análises dos resultados desta pesquisa, sugere-se, que se consolide a equidade na aplicação dos recursos, como uma possibilidade para que a gestão dos microssistemas se configure como um processo democrático. Equidade na gestão dos microssistemas significa ser imparcial na promoção e aplicação de cada atividade no ambiente da escola, sem favorecimento, mas tendo como foco o todo, sem desconsiderar as partes. Gerir a educação escolar com equidade envolve, no entanto, respeitar as diferenças, identificar e solucionar os problemas internos e procurar atender as necessidades da educação local. A gestão, nesse sentido, será vista como um ato democrático ao agir com efetividade, igualdade e qualidade na gestão dos microssistemas no ambiente escolar.

Portanto, as potencialidades da gestão escolar, na globalização, podem se configurar na consideração de todos os contextos e diversidades presentes dentro do ambiente escolar, como fatores relevantes, na execução do seu papel no desenvolvimento da educação local e global. Para isso, democratizar é preciso, a partir do planejamento e a elaboração participativa na elaboração do projeto pedagógico, bem como, da correta execução, da avaliação e reavaliação das decisões estabelecidas. Desta forma, a escola, por meio do projeto pedagógico e da gestão, contribuirá para a emancipação do aluno e para a participação como ser ativo e não a domesticação do mesmo, apenas, para a obediência.

Desta forma, a autonomia da gestão escolar pode minimizar os problemas locais por meio da gestão dos sistemas e microssistemas adequada a realidade do ambiente da escola, para que haja maior interação entre o espaço físico, o projeto pedagógico e os alunos.

Portanto, o sucesso da gestão escolar permeia o sucesso da pessoa e do profissional formado por ela, e este depende da qualidade do ambiente escolar e os microssistemas geridos pela gestão.

\section{Referências}

CHIZZOTTI, Antônio. Pesquisa qualitativa em ciências humanas e sociais. Petrópolis: Vozes, 2006.

DOURADO, Luiz Fernandes. Políticas e gestão da educação básica no Brasil: limites e perspectivas. Educ. Soc. [online], v. 28, n. 100, 2007, p. 921-946.

GALVÃO. Isabel, Expressividade e emoção: ampliando o olhar sobre as interações sociais. Rev. Paul. Educ. Fís., São Paulo, 2001, p. 15-31.

GERIR. Pedagogia de Projetos, Salvador, v. 9, n. 29, 2003, p. 17-37. Disponível em: <http://www.liderisp. ufba.br/modulos/pedagproj.pdf>. Acesso em: 22 abr., 2011.

KREBS, Rui Jornada; COPETTI, Fernando; BELTRAME, Thais Silva. Uma releitura da obra de Urie Bronfenbrenner: a teoria dos sistemas ecológicos. In: KREBS, Ruy J. Teoria dos sistemas ecológicos: um novo paradigma para a educação infantil. Santa Maria: Kinesis, 1997, p. 17-40. 
KREBS, Rui Jornada; COPETTI, Fernando; BELTRAME, Thais Silva. A criança e o esporte: reflexões sustentadas pela teoria dos sistemas ecológicos. In: KREBS, Rui Jornada; COPETTI, Fernando; BELTRAME, Thais Silva; PINTO, R. E. Os processos desenvolvimentais na infância. Florianópolis: Udesc, 2003, p. 91-104

KREBS, Rui Jornada; COPETTI, Fernando; BELTRAME, Thais Silva. Urie Bronfendbrenner e a ecologia do desenvolvimento humano. Santa Maria: Casa Editorial 1995.

MARTINS, Edna; SZYMANSKI, Heloisa. A abordagem ecológica de Urie Bronfenbrenner em estudos com famílias. Estud. Pesqui. Psicol. Uerj, 2004, p. 63-77.

MELLO, Guiomar Namo; SILVA. Rose Neubauer da. A gestão e a autonomia da escola nas novas propostas de políticas educativas para a América Latina. Estud. Av. [online], v. 5, n. 12, 1991, p. 45-60.

MORAIS, Marcus Vinícius Marques de; RANIERO Elaine Pereira; TUDELLA Eloísa; MORAIS, Janaina R. de; BARTOLIN Paula; MARTINS, Juliana G. Abordagem maturacionista: histórico e contribuições. Disponível em: <www.fsba.edu.br/dialogos possiveis>. Acesso em 20 abr. 2011.

PRATI, Laíssa Eschiletti; COUTO. Maria Clara P. de Paula, MOURA. Andreína; POLETTO. Michele; KOLLER. Sílvia Helena. Revisando a inserção ecológica: uma proposta de sistematização. Psicologia: Reflexão e Crítica, v. 21, n. 1 2011, p. 160-169. Disponível em: <www.scielo.br/prc>. Acesso em: 22 abr. 2011.

SATO, Michèle. Educação ambiental. São Carlos: Rima, 2003

VEIGA, IIma Passos Alencastro (org.). Escola do projeto político pedagógico. Campinas: Papirus, 2008.

VIÉGAS, Lygia de Sousa. Reflexões sobre a pesquisa etnográfica em educação e psicologia. Disponível em: <www.fsba.edu.br/dialogospossiveis $>$. Acesso em: 20 abr. 2010.

VIÉGAS, Lygia de Sousa. Gestão, avaliação e sucesso escolar: recortes da trajetória cearense. Estud. Avançados, 2007, p. 21-60.

ZANLORENÇO, Margarete Kossowski; SCHNEKENBERG, Marisa. Liderança e motivação na gestão escolar: o trabalho articulador dos diretores das escolas municipais. Revista Eletrônica Lato Sensu, v. 3, n. 1, 2008. Disponível em: http://www.unicentro.br. Acesso em: 22 abr. 2011.

Vonínio Brito de Castro é professor no Instituto Federal de Educação, Ciência e Tecnologia do Tocantins - campus Porto Nacional, mestre em Ciências do Ambiente e Sustentabilidade na Amazônia pela Universidade Federal do Amazonas.

Endereço: 607 Norte, Alameda 16, Lote 2, Qi-18 - 77001-713 - Palmas TO - Brasil.

E-mail: voninio@yahoo.com.br. 
Marta Roseli de Azeredo Barichello é professora na Universidade Federal de Santa Maria, doutora em Educação pela Universidade do Vale do Rio dos Sinos.

Endereço: Vila Medianeira - 97220-000 - Faxinal do Soturno - RS - Brasil. E-mail: martabar@ibest.com.br.

Recebido em 10 de julho de 2013.

Aceito em 10 de agosto de 2013. 